\title{
A Net Map Method on Vehicle Structural Fatigue Damage Analysis
}

\author{
Liu Yongchen", Sun Li and Xu Lichao
}

\author{
Faculty of Transportation Engineering, HuaiYin Institute of Technology, Huai'an, 223003, China
}

\begin{abstract}
In order to effectively use the vehicle road test load spectrum data and adjust road test specifications, a net map method on vehicle structural fatigue damage analysis is proposed, by taking the vehicle subframe as a study objective. This article consists of three parts. First part discusses that, the finite element analysis model of the vehicle subframe was built in ANSYS software, and its construction stress was calculated and analyzed under the action of lateral and longitudinal forces, respectively. The hot points on the control arm were determined, which could bring about fatigue damage. The location was identified as load testing point $P$, where strain rosette was pasted. Second part discusses that, the strain load of the subframe was measured under the condition of proving ground, eight kinds of roads that fall under combination roads were chosen in the proving ground and the vehicle speed was found to be different on each road. After finishing the data processing, and the pure signal of vehicle subframe was acquired. Using rain flow counting method, the load spectrum of the subframe was worked out, and load distribution histogram on the testing point was obtained. On this basis, according to local stress-life method and Miner standard and stress concentration correction factor, the fatigue damage analysis was completed for the subframe under the combination road and each of the enforced roads. Third part discusses that, the fatigue damage density and weight of each road conditions were calculated under the condition of each enforced road about subframe structure, and a net map that represented its closed area fatigue damage was drawn. In the net map, the central angle represents the damage weights on different road conditions and the radius length represents the damage density on each road. The results show that the network diagram can easily express the vehicle structural damage under the conditions of all the different combination of roads when the size of the central angle and length of radius were changed, vehicle structure damage relative to the change would be obtained by drawing a new net map. This method provided a convenient and effective way to analyze vehicle fatigue damage.
\end{abstract}

Keywords: Damage analysis, Structure fatigue, Net map method, Vehicles.

\section{INTRODUCTION}

In the reliability design of the vehicle product development stage, the fatigue durability of the road needs to be tested according to the road specifications, the fatigue strength of vehicle and its important components, and estimate the fatigue life. At present, research is being conducted on the fatigue durability of the vehicle structure, in the process of product development. The automobile manufacturers carry out a wide range of automobile road tests and there are many related literatures regarding road durability tests and studies under field loadings. Test process of studies on durability of automobile has to follow the unified standard and specifications [1-4]. The models developed for different purposes and different users have certain limitations. In addition, in the evaluation of fatigue damage process of vehicle components, method applied in the tests are used for production or verification. The testing time is long and the test data only solves one single problem, which cannot be solved merely by analyzing problem through comparing the same products, or through analogy analysis of the problem for different products under the same conditions [5-9].

*Address correspondence to this author at the Faculty of Transportation Engineering, HuaiYin Institute of Technology, MeiCheng East Road, Huaian, Postcard: 223003, China; Tel: 13952396525;

E-mail: jlyslyc@sina.com
In order to realize comparison analysis of vehicle structure fatigue injury under different conditions, the vehicle structure and load spectrum data is repeatedly used effectively, and adjustments are made to the fatigue durability road test specification according to the objective. In this article, the vice frame important structure of the car, was taken as the research objective and solved by the finite element analysis method. Based on actual load test of experimental field, compiling load spectrum, analysis damage and a kind of net map method of fatigue analysis of vehicle damage is put forward. Provides direct reference for the fatigue damage analysis of vehicle structure, and also provides a new experience for the research on fatigue and other important structures.

\section{VEHICLE LOAD TEST}

\subsection{The Establishment of Dimensional Model and Finite Element Model}

For determining fatigue vehicle structure damage hot position, a 3D model of front vice frame and main connector assembly is built, as shown in Fig. (1). The whole model is a symmetrical structure, each side of vice frame is connected by two hinged with the lower control arm, control arm is connected with the other end of the steering knuckle low-end hinge, so that the vice frame mainly forced by the tire lateral 
force, head of longitudinal force and vertical load of the vehicle.

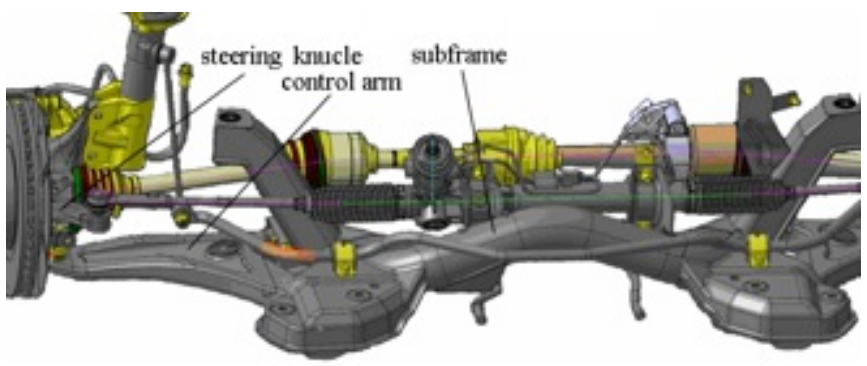

Fig. (1). A three-dimensional model of subframe.

\subsection{Determination of Structural Damage Hot Point}

In the ANSYS finite element analysis software, grid the three-dimensional model of the auxiliary frame assembly, and add constraints at the wire frame connecting points according to the actual structure (around $\mathrm{X}$ axis rotational degree of freedom), add loads according to the two conditions of lateral connections $(\mathrm{Y})$ and vertical $(\mathrm{X})$ on the head of shaft to take the finite element analysis, and the stress distribution of side frame as shown in Fig. (2). The maximum stress under the lateral load conditions is $572 \mathrm{MPa}$ $\left(9021^{\text {st }}\right.$ nodes), as shown in Fig. (3), the maximum stress under the longitudinal loading conditions $1510.2 \mathrm{MPa}$ on No. 595933 node and $916.3 \mathrm{MPa}$ on No.689812 node. After analysis, we found the maximum load location, and ultimately determine the $\mathrm{P}$ as fatigue damage hot point on the wire frame, providing reliable testing location for the load test.

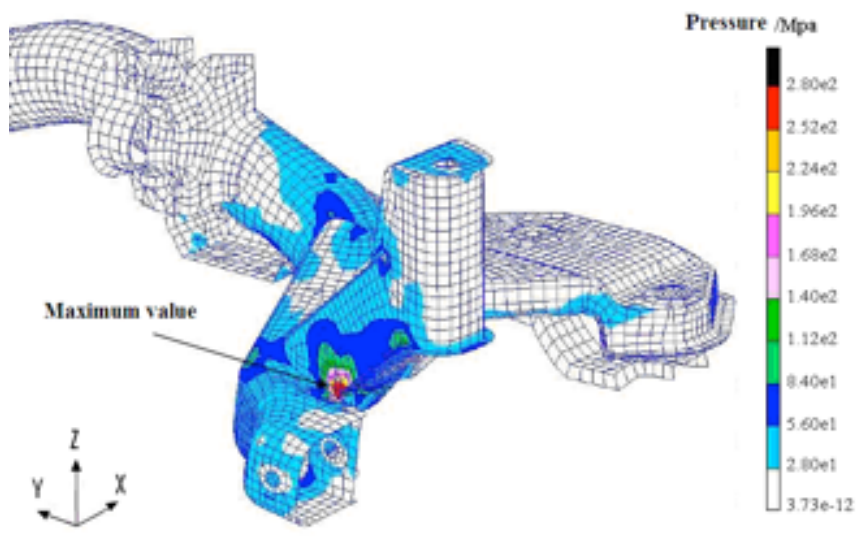

Fig. (2). The stress distribution under lateral force.

\subsection{Strain Load Test}

To obtain the accurate load of the subframe received in the vehicle operation accurately, according to the results of finite element analysis, the strain gauge should be welded at $10 \mathrm{~mm}$ and considering the convenience of the test and patch arrangement, the strain measurement in the sub frame should be the left position as shown in Fig. (4).

According to the proven ground durability test specification and test purpose, select comprehensive road in the load test, concrete road mileage and the running requirements as shown in Table $\mathbf{1}$. The main test equipment includes the resistance strain gauges and data acquisition system. Three directions (45 degrees) resist strain gauge, type of BE350-3CA, and resistance value is $350 \Omega$, using the eDAQ module data acquisition system made in America HBM-SoMat for the ADC conversion. The precision of the system is lower than $1 \%$, and the sampling frequency can reach up to $100 \mathrm{kHz}$.

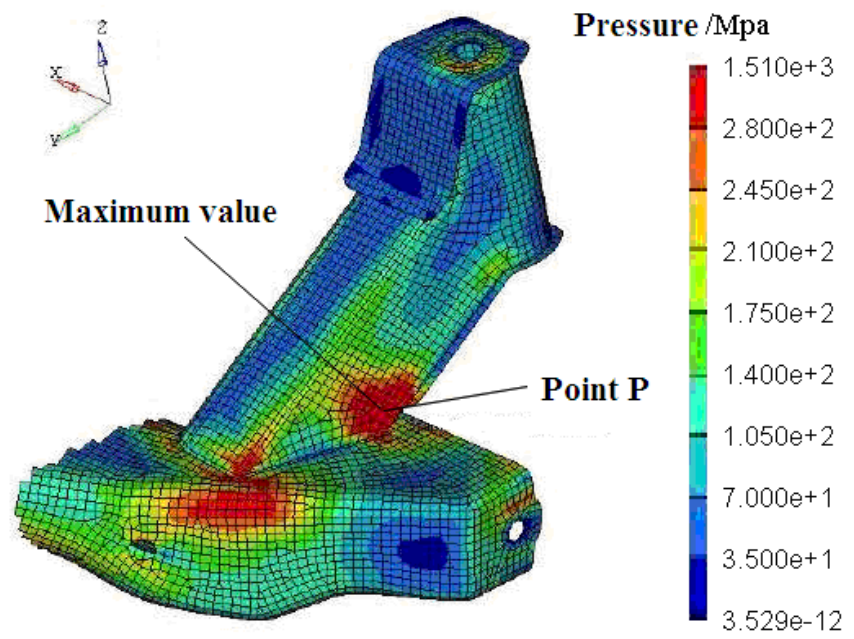

Fig. (3). The stress distribution under longitudinal force.

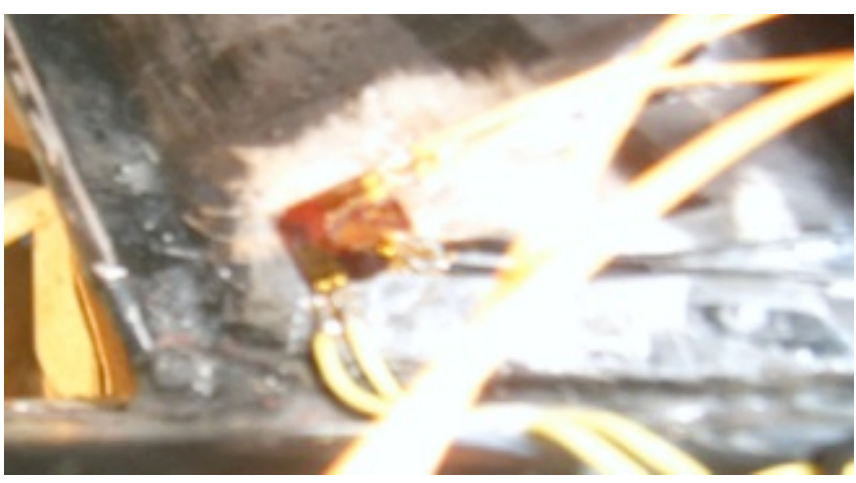

Fig. (4). Subframe strain gauge layout.

Table 1. Proving ground load testing program.

\begin{tabular}{|c|c|c|c|}
\hline Number & Road Type & Mileage/m & Speed/km/h \\
\hline \hline 1 & Twisted road b & 85 & 5 \\
\hline 2 & Stone road c & 800 & 60 \\
\hline 3 & Stone road b & 1189 & 50 \\
\hline 4 & Cobble stone road b & 335 & 60 \\
\hline 5 & Sand stone road & 2113 & 40 \\
\hline 6 & Washboard road & 700 & 50 \\
\hline 7 & Stone road c & 800 & 50 \\
\hline 8 & Long wave road & 90 & 50 \\
\hline 9 & General road & 2300 & 80 \\
\hline \multicolumn{4}{|c|}{ Total mileage } \\
\hline
\end{tabular}

The test process is as follows:

A. The basic requirements are: a driver, a vehicle and road equipment. For a new passenger vehicle, general 
quality is rated when full load and axle load quality meet the requirements such as the standard tire pressure etc. The driver from the test field needs to select the test route of the Ministry of Transportation's highway traffic testing field.

B. Strain gauge installation and collector set: Strain gauges and data acquisition system are installed after polishing, cleaning, marking, pasting, checking, sealing and other steps. Eliminate the wire resistance on each channel and set the channel parameters at a sampling frequency of $500 \mathrm{~Hz}$.

C. Pre-test and analysis. Select the typical road and try to collect some small signal, observe the rationality and availability of signal.

D. Road load test. According to the provisions of sections, ensure proper speed and security number of samples. Test the load signal 6 times and check the data and equipment status at the end of each test.

Pure load signal is obtained based on the subframe test signal analysis and processing, as shown in Fig. (5).

\section{THE PREPARATION OF VEHICLE LOAD SPECTRUM}

After filtering and removing singular values, the test signal needs maximum principal for measuring point position of the stress. The fatigue load spectrum is obtained by means of the rain flow counting method of the statistics cyclic loading.

\subsection{The Maximum Principal Stress Calculation}

According to the strain gauge type, use the test strain results to obtain the maximum principal strain by type (1).

$\varepsilon_{1,3}=\frac{\varepsilon_{0^{\circ}}+\varepsilon_{90^{\circ}}}{2} \pm \sqrt{\left(\frac{\varepsilon_{0^{\circ}}-\varepsilon_{90^{\circ}}}{2}\right)^{2}+\left(\frac{\varepsilon_{0^{\circ}}+\varepsilon_{90^{\circ}}-2 \varepsilon_{45^{\circ}}}{2}\right)}$

where, $\varepsilon_{1,3}$ is measuring point maximum, minimum principal strain.

$\varepsilon_{0^{\circ}}$ is measuring point strain flower 0 degree direction value.

$\varepsilon_{45^{\circ}}$ is measuring point strain flower 45 degree direction value.

$\varepsilon_{90^{\circ}}$ is measuring point strain flower 90 degree direction value.

According to Hooke's law, namely type (2) is used to obtain the maximum principal stress, in order to get the maximum principal stress, and the calculation results of the measuring point P3 are shown in Fig. (6).

$\sigma_{1,3}=E \cdot \varepsilon_{1,3}$

where, $\mathrm{E}$ is the elastic modulus, equal to $2.10 \mathrm{e} 5 \mathrm{MPa}$.

\subsection{The Rain Flow Counting Method}

The work load on many of the mechanical components in practical engineering is a random process. It is usually analyzed by statistical method. The rain flow counting

a. rosette 0 degree direction

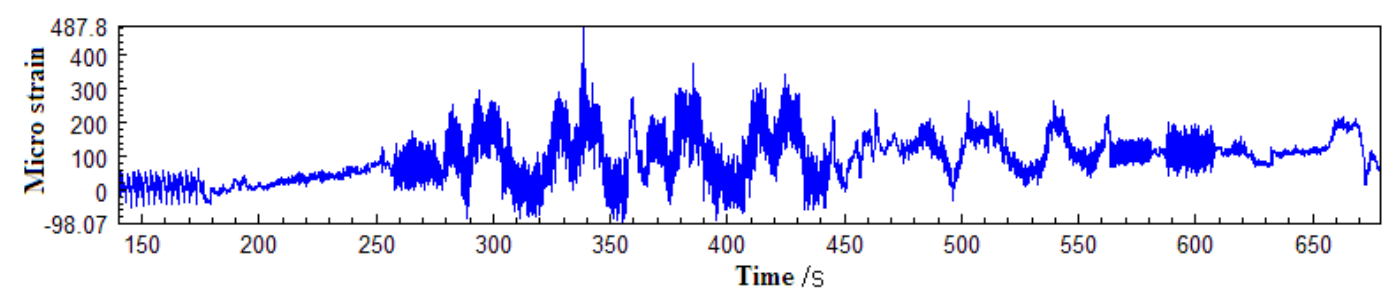

b. rosette 45 degree direction

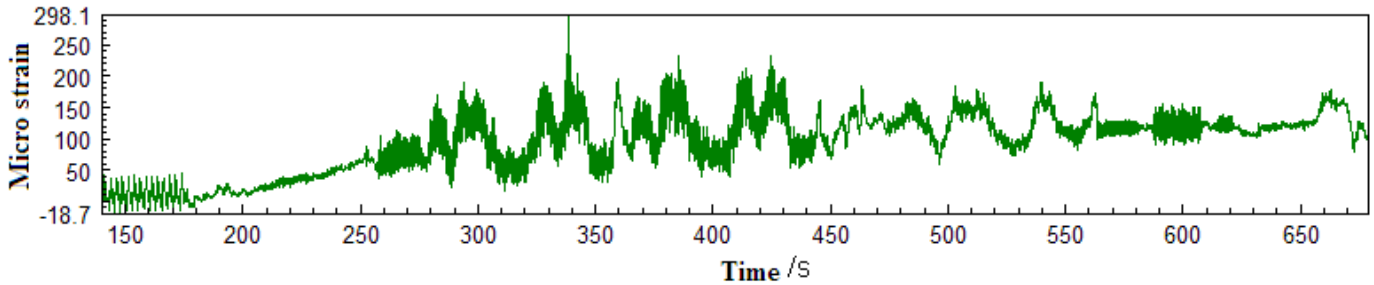

c. rosette 90 degree direction

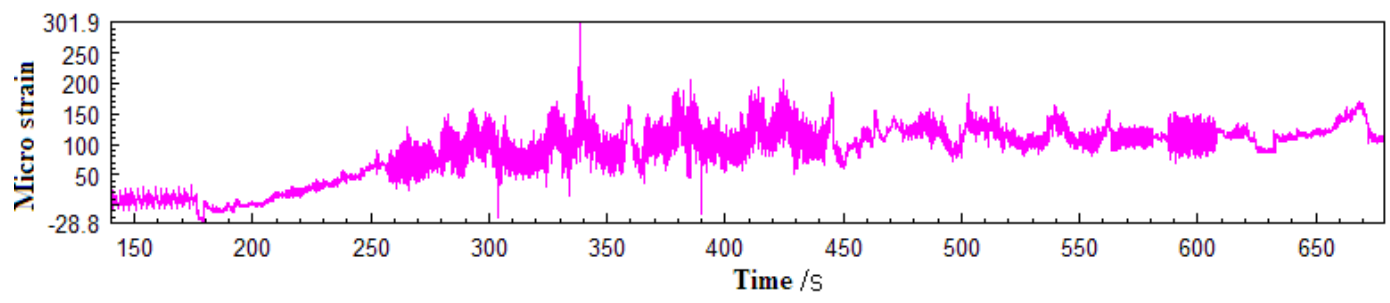

Fig. (5). Load test pure signal on subframe P point. 
method is a method widely used in numerous counting methods. The 3D data of amplitude and location of average load can also be acquired through rain flow counting method [10-12].

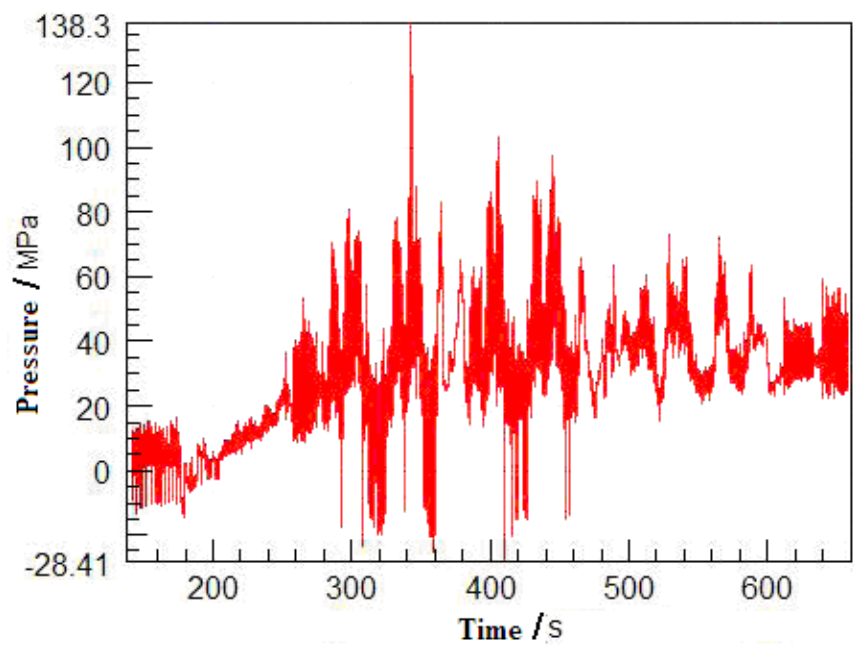

Fig. (6). Maximum principal stress calculations on $P$ point.

After the count cycle of random load signals, in order to obtain the load amplitude and frequency information, we can get a rain flow matrix as seen in Fig. (3).

$$
R(i, j)=\left[\begin{array}{ccccc}
r_{11} & r_{12} & \ldots & r_{1 j} & r_{1 u} \\
r_{21} & r_{22} & \ldots & r_{2 j} & r_{2 u} \\
\vdots & & & & \\
r_{i 1} & r_{i 2} & \ldots & r_{i j} & r_{i u} \\
\vdots & & & & \\
r_{v 1} & r_{v 2} & \ldots & r_{v j} & r_{v u}
\end{array}\right]
$$

where, $R(i, j)$ is the rain flow matrix.

$i$ is the rain flow cycle load level point.

$j$ is the rain flow cycle closure point.

$r_{i j}$ is the rain flow cycle start with $\mathrm{i}$ and end with $\mathrm{j}$.

$u, v$ is the rain flow matrix and the number of lines.

\subsection{The Rain Flow Counting Results}

The load spectrum cycle counting was completed for the measuring point by using the software of ncode's glyghworks. Mean amplitude two-dimensional frequency histogram can respectively be generated, as shown in Fig. (7). The rain flow matrix will be imported into the excel table of $64 * 64$ and saved as MATLAB format file.

The statistical distribution frequency of rain flow counting should be done according to the construction experience, using statistical hypothesis to test to determine the load average according with normal distribution and load amplitude Weibull distribution. a. Rain flow counting statistics results

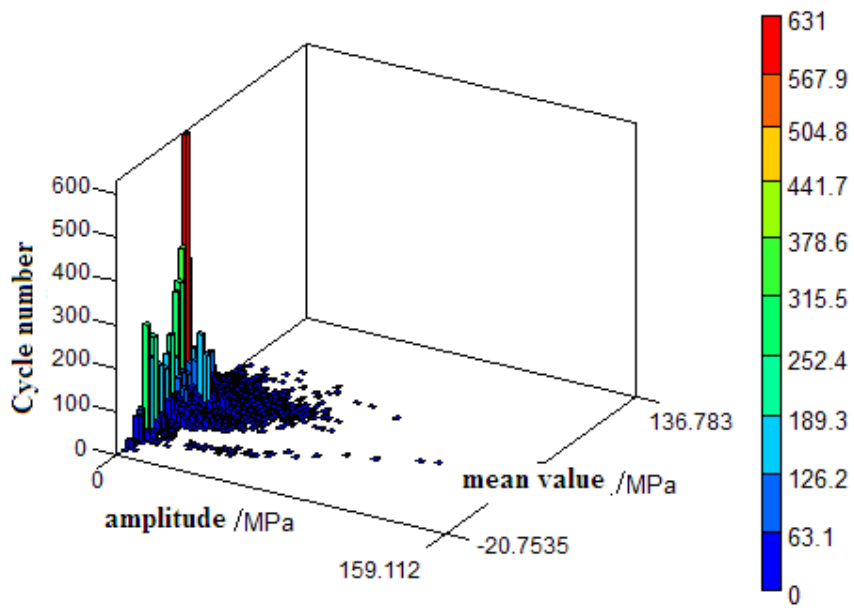

b. Amplitude distribution

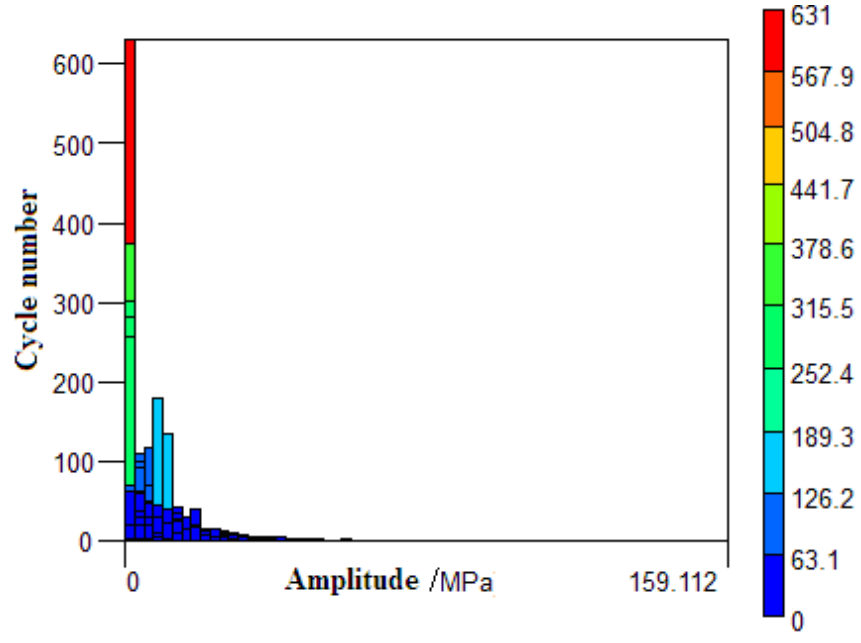

c. Average value distribution

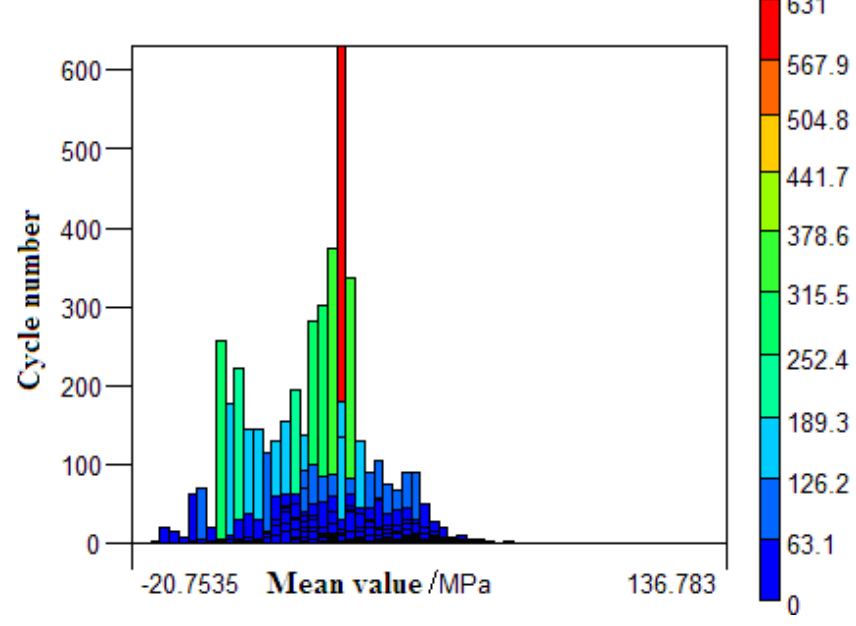

Fig. (7). Rain flow counting histogram on $P$ point. 


\section{THE CALCULATION OF VEHICLE FATIGUE DAMAGE}

\subsection{Miner Standards}

According to the actual load spectrum, calculate fatigue damage of structure and damage of each load cycle fatigue is $D_{i}$,

$D_{i}=\frac{1}{N_{f i}} \quad(i=1,2, L, M)$

According to the Miner linear fatigue damage accumulation criterion [13,14], fatigue damage resulting in the parts in load process can be expressed as $D$,

$D=\sum_{i=1}^{M} D_{i}=\sum_{i=1}^{M} \frac{1}{N_{f i}}$

When engineering analysis, according to the experience, material fatigue damaged occurs when the $\mathrm{D}=1$.

\subsection{Structure Stress Concentration Correction}

According to the actual structure of auxiliary frame and control arm, all measuring points have stress concentration, and in the process it should not coincide with the stress concentration position completely, So when the fatigue life estimation is being measured, the stress concentration should be corrected generally by fatigue notch factor $K_{f}$, which is,

$K_{f}=1+q \cdot\left(K_{\sigma}-1\right)$

where, $\mathrm{q}$ is notch sensitive coefficient, which is related to material and structure that can be determined by type (7); $K_{\sigma}$ is an effective stress concentration factor and can be determined by type (8).

The notch sensitive coefficient q can be obtained from the Peter Son empirical formula, which is,

$q=\frac{1}{1+P / r}$

where, $p$ is the characteristic length associated with the material value of $10 \mathrm{~mm}$;

$r$ is the root of notch radius structure, $\mathrm{p}=6 \mathrm{~mm}$.

For tension and compression or bending loading, the effective stress concentration coefficient $K_{\sigma}$ can be calculated by the formula (8), i.e.

$K_{\sigma}=1+q \cdot\left(\alpha_{\sigma}-1\right)$

where, $\sigma$ is material concentration coefficient, take 2 after looking for the mechanical design manual.

Measuring point $\mathrm{P}$ fatigue notch factor is 1.14 by formula (6) (8).

\subsection{The Calculation of Vehicle Structure Fatigue Damage}

This paper uses ncode 8.0 glyghworks fatigue analysis software, and the stress life method, fatigue damage and life estimation procedures, for calculating the fatigue notch factor input to obtain the total damage value of subframe $\mathrm{p}$, and damage value for each kind of road in this load spectrum can be seen in Table 2.

Table 2. Subframe fatigue damage value.

\begin{tabular}{|c|c|c|}
\hline Number & Road Type & Damage Value \\
\hline \hline 1 & Twisted road b & $7.81 \mathrm{E}-07$ \\
\hline 2 & Stone road c & $6.22 \mathrm{E}-07$ \\
\hline 3 & Stone road c & $1.28 \mathrm{E}-06$ \\
\hline 4 & Pebble road b & $1.05 \mathrm{E}-07$ \\
\hline 5 & Sand stone road b & $3.62 \mathrm{E}-07$ \\
\hline 6 & Washboard road b & $5.89 \mathrm{E}-07$ \\
\hline 7 & Long wave road b & $4.36 \mathrm{E}-08$ \\
\hline 8 & General road & $4.70 \mathrm{E}-09$ \\
\hline \multicolumn{2}{|c}{ Total damage } \\
\hline
\end{tabular}

\section{THE NET MAP REPRESENTATION OF VEHICLE FATIGUE DAMAGE}

To further analyze the effect of each test road on vehicle subframe structure fatigue damage, in the cycle of test, i.e. in every test specification for the test road, the fatigue damage of the main vehicle structure for each pavement condition was calculated. Then the fatigue damage contribution rate and weighted average of each road according to the rate of total damage in the testing period were calculated, as shown in Table 3.

In Table 3, each reinforced pavement damage density was calculated, which is damage value per unit mileage, for the specific vehicle structure, that is only related to strength of pavement types. It can be a more convenient representation of fatigue damage of the vehicle structure caused by road roughness.

The different automobile enterprises have been designed according to the needs of different car users, which can be: the need to examine the fatigue damage of different test road on the structure, or the need to adjust the test field of different road test specifications and lastly the need to refrain from conducting the tests again and again. According to fatigue damage weight and damage density results given in Table 3, the mesh of computation of fatigue vehicle structure damage is concerned with the central angle which represents different road weights and radius length damage density for different road conditions. In a net map, a closed area means fatigue damage which has been caused by strengthening road which has different contribution rates in 
Table 3. Fatigue damage caused by proving ground road.

\begin{tabular}{|c|c|c|c|c|}
\hline Number & Road Type & Attribution Rate \% & Weighted & Damage Density \\
\hline \hline 1 & Twisted road b & 21.3 & 0.213 & $3.37 \mathrm{E}-06$ \\
\hline 2 & Stone road c & 16.14 & 0.161 & 0.335 \\
\hline 3 & Stone road c & 33.45 & 0.024 & $5.29 \mathrm{E}-06$ \\
\hline 4 & Pebble road b & 2.36 & 0.090 & $3.73 \mathrm{E}-07$ \\
\hline 5 & Sand stone road b & 8.98 & 0.164 & $1.42 \mathrm{E}-06$ \\
\hline 6 & Washboard road b & 16.35 & 0.013 & $2.58 \mathrm{E}-06$ \\
\hline 7 & Long wave road b & 1.26 & 0.001 & $1.99 \mathrm{E}-07$ \\
\hline 8 & General road & 0.112 & $1.77 \mathrm{E}-08$ \\
\hline
\end{tabular}

vehicle structure road test cycle. When there is a need to calculate proportion changes in the vehicle in the structural damage caused by different pavements, only the central angle size in the net map needs to be changed. There is also a need to consider the different strengthen pavement action sequence effects on vehicle fatigue damage, in which case the only thing needed to change is the corresponding position of the angle of center of the circle in the net map. This also gets a closed area in net map.

For the convenience of drawing a net map, the regional value partition according to the actual size of damage density is plotted on the road test cycle, as shown in Table 3. Damage density divided by 100 interval is shown in Table 4 .

Table 4. Damage density region.

\begin{tabular}{|c|c|c|c|c|c|}
\hline Damage Density & $\begin{array}{c}\mathbf{( 5 \sim 9 . 9 )} \\
\text { E-06 }\end{array}$ & $\begin{array}{c}\mathbf{( 1 \sim 5 )} \\
\text { E-06 }\end{array}$ & $\begin{array}{c}\mathbf{( 5 \sim 9 . 9 )} \\
\text { E-07 }\end{array}$ & $\begin{array}{c}\mathbf{( 1 \sim 5 )} \\
\text { E-07 }\end{array}$ & $\begin{array}{c}\mathbf{( 1 \sim 4 . 9 9 )} \\
\text { E-08 }\end{array}$ \\
\hline \hline Percent-age & $95 \sim 100$ & $90 \sim 95$ & $85 \sim 90$ & $80 \sim 85$ & $60 \sim 65$ \\
\hline
\end{tabular}

Thus to determine the percentage damage density produced under the pavement, rounding up is shown in Table 5.

According to the weighted average of various reinforced pavements shown in Table $\mathbf{4}$ and the damage density percentile shown in Table 5, the subframe $\mathrm{P}$ fatigue damage at the net map is rendered. The central angle is the weight, and radius of the circle is the damage density percentage. Radius density score points are sequentially connected. And the area that is formed is the total score of fatigue damage on all kinds of strengthen road, as shown in Fig. (8). Figure number represents strengthen pavement type in Table $\mathbf{2}$.

The net map can be conveniently used to express relative changes in contrast vehicle structure fatigue damage under conditions of different types of strengthen pavement weight and the sequence changes.

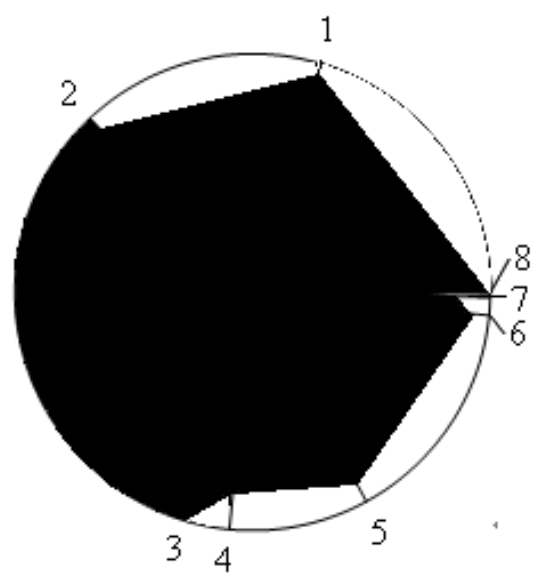

Fig. (8). Subframe fatigue damage network diagram.

\section{CONCLUSION}

This article addresses the vehicle fatigue damage analysis using structural damage representation method, and through research (also mentioned in the article) the following conclusion has been reached:

1) The method of finite element analysis can be used to determine the exact location of fatigue damage on the vehicle structure. This method provides reliable positions for load testing, and also determines the sub frame fatigue risk points which are in the inclined column root.

2) Under the test strengthen road conditions: The actual load spectrum, which has been done by using the fatigue life of stress, the accumulated damage criterion and the subframe fatigue notch stress concentration correction. The total damage of the subframe is calculated under various strengthen road conditions and circular road condition.

Table 5. The damage density percentile on test enhanced pavement.

\begin{tabular}{|c|c|c|c|c|c|c|c|c|}
\hline Road Type & Twisted Road & Stone Road c & Stone Road b & Pebble Road b & Sand Stone Road & Washboard Road b & Long Wave Road b & General Road \\
\hline Integer value & 94 & 93 & 100 & 84 & 92 & 93 & 82 & 62 \\
\hline
\end{tabular}


3) In order to calculate the damage density under enhanced conditions, the damage weight needs to be taken as the central angle, and the damage density percentage needs to be taken as the radius to draw net map, in which the closed area represents fatigue damage of sub-frame.

\section{CONFLICT OF INTEREST}

The authors confirm that this article content has no conflict of interest.

\section{ACKNOWLEDGEMENTS}

The authors gratefully acknowledge the sponsorship and support from Six Kinds Talent Summit Project of Jiangsu Province (2014-JXQC-007), Qing Lan Project of Jiangsu Province, and the Natural Science Foundation of the Jiangsu Higher Education Institutions of China (13KJB580001).

\section{REFERENCES}

[1] F. Huo, Y. Kang, and D. Wei, "Life prediction of car transmission case with actual measured load spectrum," Journal of Machine Design, vol. 29, pp. 84-85, 2012.

[2] H. Guo, W. Chen, and X. Fan, "Research of enhancement coefficient of automobile reliability enhancement test on proving ground", Chinese Journal of Mechanical Engineering, vol. 40, pp. 72-75, 2004

[3] Y. Liu, G. Wang, and L. Sun, "Fatigue damage analysis and life prediction for vehicle control arm", Transactions of the Chinese Society of Agricultural Engineering, vol. 29, pp. 83-89, 2013.
[4] Z. Lu, and Y. Hu, "The dynamic stress simulation and fatigue life calculation of key parts and components based on rigid flexible coupling system", Rolling Stock, vol. 44, pp. 6-15, 2006.

[5] W. Hu, M. Yi, and X. Jin, "Study on road simulation for front-body of car", Journal of Tongji University, vol. 31, pp. 861-863, 2003.

[6] J. Wu, H. Zhou, and H. Dong, "Study on road equivalent simulation based on loading spectrums in customer road and proving ground", Automobile Technology, pp. 21-23, 2007.

[7] M. Zhu, M. Xiong, and Z. He, "Fatigue analysis for leaf spring", Transactions of the Chinese Society for Agricultural Machinery, vol. 37, pp. 149-154, 2006

[8] R. Liang, M. Li, and X. Guo, "Research on load spectrum reconstruction method of road simulation based on RPC", Automotive Science and Technology, pp. 42-43, 2008.

[9] X. Li, N. Huo, and J. Tian, "Dynamic load simulation and fatigue life calculation of pivotal load carrying structure of air suspension system", Journal of Jilin University (Engineering and Technology Edition), vol. 41, pp. 12-26, 2011.

[10] W. Li, C. Zhang, and Q. Song, "2-D for motor propulsion system on hybrid electric vehicle", Transactions of the Chinese Society for Agricultural Machinery, vol. 41, pp. 21-24, 2010.

[11] Y. Zhang, G. Wang, and J. Wang, "Compilation method of power train load spectrum of engineering vehicle", Transactions of the Chinese Society of Agricultural Engineering, vol. 27, pp. 179-185, 2011.

[12] Y. Ge, and J. Wang, "Fuzzy reliability optimization design of the cutter shaft of the whole rice straw returning machine", Transactions of the Chinese Society of Agricultural Engineering, vol. 24, pp. 123-124, 2008.

[13] Y. Li, J. Tian, and Z. Zhao, "Fatigue analysis of gears in combine harvester chassis gearbox", Transactions of the Chinese Society of Agricultural Engineering, vol. 27, pp. 106-115, 2011.

[14] L. Zhang, S. Liu, and E. Mao, "Reliability analysis of agricultural machinery chassis drive axle housing based on ANSYS", Transactions of the Chinese Society of Agricultural Engineering, vol. 29 , pp. 37-38, 2013 